\title{
Computer Coding Scavenger Hunt using Quick Response Codes (Resource Exchange)
}

\section{Dr. Stephany Coffman-Wolph, Ohio Northern University}

Dr. Stephany Coffman-Wolph is a Visiting Assistant Professor at Ohio Northern University in the Department of Electrical, Computer Engineering, and Computer Science (ECCS). Research interests include: Artificial Intelligence, Fuzzy Logic, Game Theory, Teaching Computer Science, STEM Outreach, Increasing diversity in STEM (women and first generation), and Software Engineering.

\section{Dr. Kimberlyn Gray, West Virginia University Institute of Technology}

Dr. Kimberlyn Gray is an Assistant Professor at West Virginia University Institute of Technology in the department of Chemical Engineering. She coordinated STEM outreach for the Leonard C. Nelson College of Engineering and Sciences. 


\section{COMPUTER

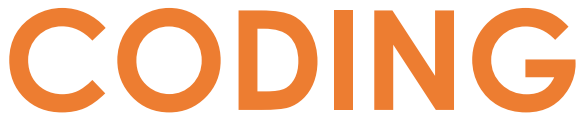 \\ SCAVENGER HUNT USNG \\ QUICK RESPONSE CODES}

ASEE 2020 | STEPHANY COFFMAN-WOLPH | KIMBERLYN GRAY

\section{PCEE DIV | OHIO NORTHERN UNIVERSITY | WVU INSTITUTE OF TECHNOLOGY}

Example C++ Code from the Harry Potter Coding Scavenger Hunt

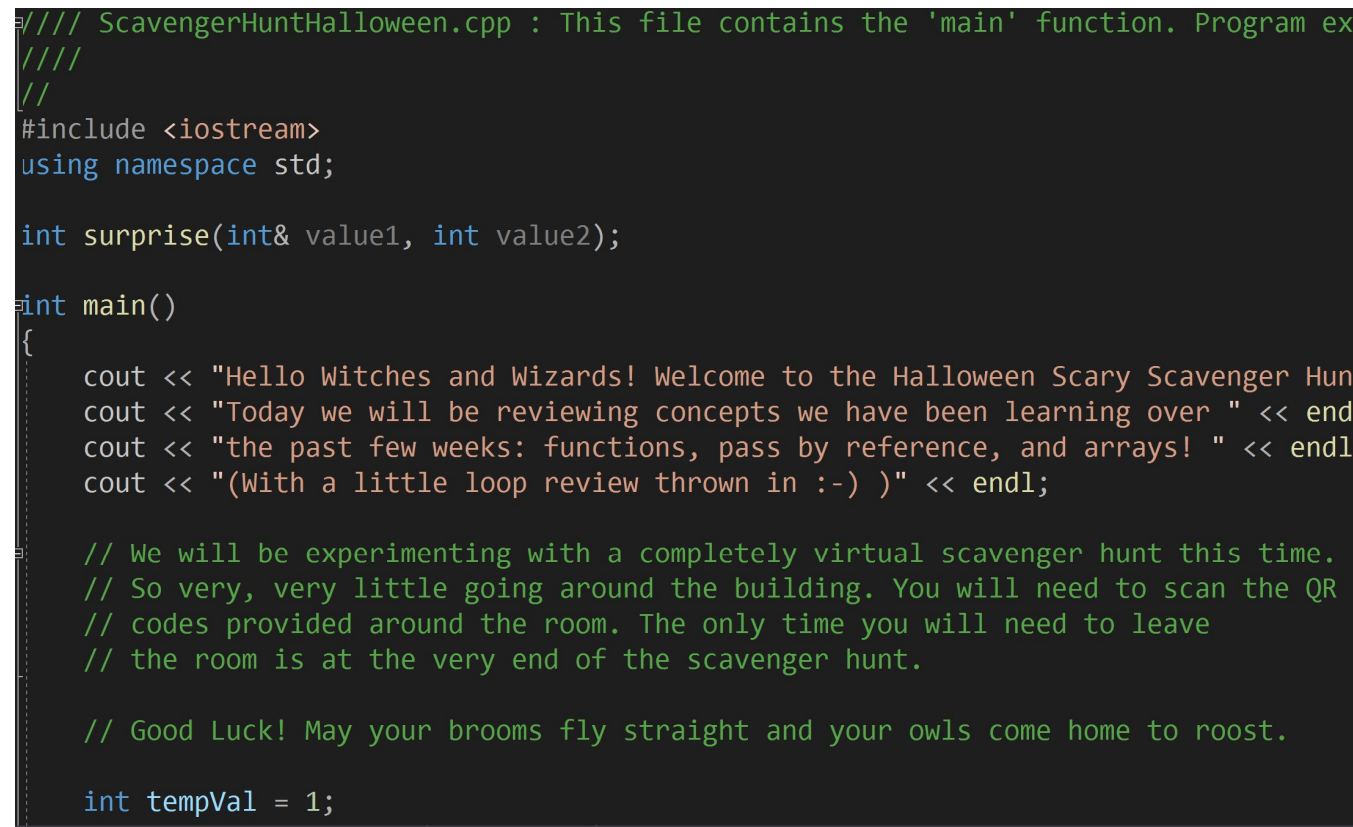

ESSENTIAL SKILLS

- Problem solving

- Teamwork

- Understanging syntax

-Interpreting code

\section{PURPOSE}

- Active learning

activity to have

students practice

reading code and not

using the compiler to

predict the outcome

\section{INTRODUCTION AND SAMPLE ACTIVITY}

Teaching computer programming can be challenging and difficult to make exciting. A scavenger hunt can engerize the classroom and will get students up and moving around. This novel use of normal course materials is easy to create, easy to set up in any classroom, easy to relocate, and requires no re-set time between uses.

The QR codes are used to deliver the clues or allow the students to "check-in" at each step.
The students act as the computer and interpret the code (clues) to find the next clue (i.e., next colored QR code and/or location) in the hunt.

The supplied 5 clue $\mathrm{C}++$ Harry Potter Halloween Themed scavenger hunt covers: variable declaration, Strings, assignment statements, print statements, if statements, computer arithematic, case/switch statements, arrays, loops, pass by value vs. pass by reference, casting to different data types, ASCII, and functions.

\section{INCLUDED}

-All materials for a

C++ Harry Potter

themed code

scavenger hunt are supplied including:

$\checkmark$ C++ Code

$\checkmark$ QR Codes

$\checkmark$ Lesson Plans

Background Info

FAQs

$\rightarrow$ Classroom Script 
PURPOSE: PROVIDE FUN HANDS-ON

\section{ACTIVITIES FOR MIDDLE AND HIGH}

SCHOOL TEACHERS AND CS OUTREACH

\section{PRACTITIONERS}

These scavenger hunts are flexible in time length so that they can be simply added to ongoing class curriculums or during a computer/technology week.

We provide suggestions, samples for an engineering math scavenger hunt, and tips for creating scavenger hunts for a variety of STEM fields.

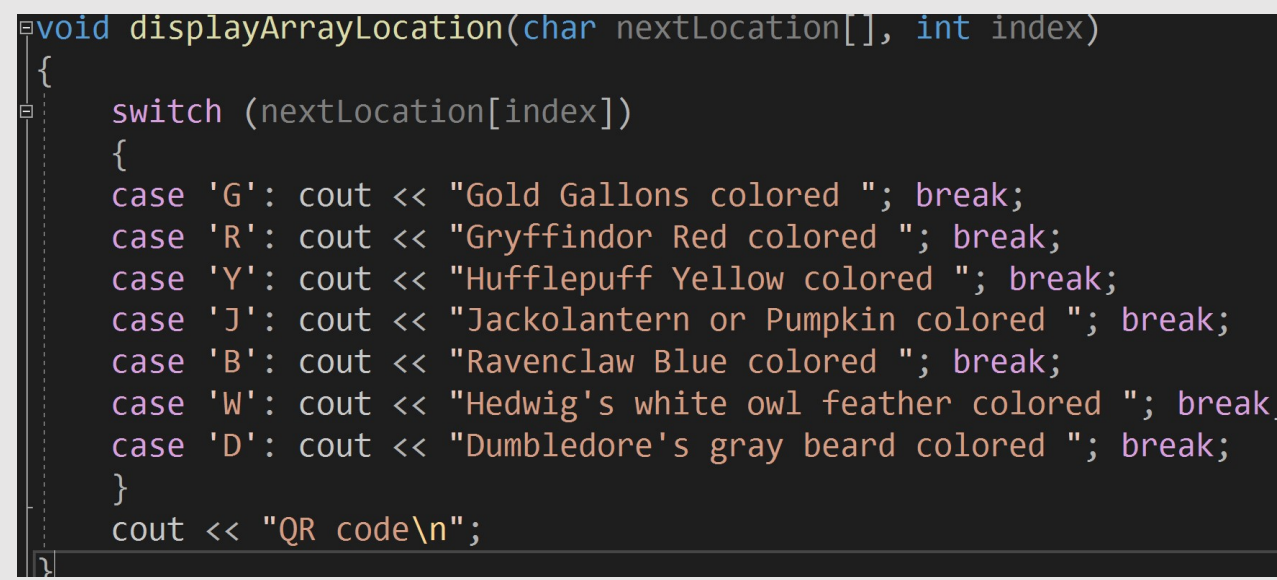

\section{Grade Level Recommendations:}

Middle or High School, College Freshman

Need Materials:

Materials: (1) colored printer ink or color copier,

(2) $8.5 \times 11$ white paper, and (3) tape
Contact Informaiton:

-s-coffman-wolph@onu.edu

>kimberlyn.gray@mail.wvu.edu

Google Drive with Materials: https://tinyurl.com/r6gw5rt

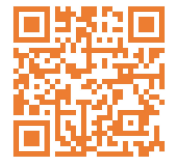

\section{COMMON CORE}

\section{STANDARDS COVERED}

\section{1}

Follow precisely a multistep procedure when carrying out experiments, taking measurements, or performing technical tasks.
02

Engage effectively

in a range of

collaborative

discussions with

diverse partners on topics, texts, and issues, building on others' ideas and expressing their own clearly
Common Core Citation: National Governors Association Center for Best Practices, Council of Chief State School Officers, "Common Core State Standards" National Governors Association Center for Best Practices, Council of Chief State School Officers, Washington D.C., 2010.

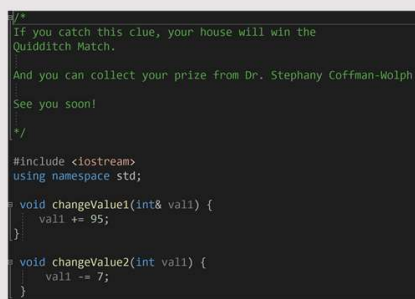

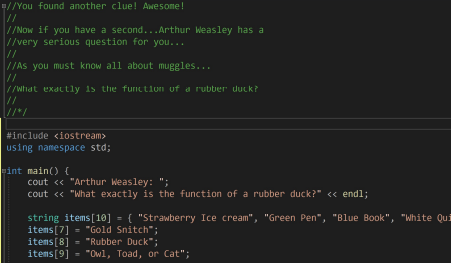

SCAN ME 回保回 